\title{
A INVISIBILIDADE DO ALUNO DE CLASSE BAIXA EM SALA DE AULA: OUTRO OLHAR SOBRE O FRACASSO ESCOLAR
}

\section{THE INVISIBILITY OF THE LOW-CLASS STUDENT IN A CLASSROOM: ANOTHER LOOK AT THE SCHOOL FAILURE}

\author{
BASTOS, Nathália Masson ${ }^{1}$ \\ SILVA, Gabrielle Luz Brasil ${ }^{2}$
}

\section{RESUMO}

Este artigo parte de uma reflexão antropológica-visual sobre o "poder do olhar". Entende-se que a questão do olhar reflete relações de poder e as consolidam. Aqui delimitou-se analisar a questão do "olhar" nas relações de poder no espaço escolar, especificamente perante o aluno de condições desprivilegiadas por se entender que este é objeto de um olhar que o constitui em sua alteridade. Objetiva-se investigar o como, como a invisibilidade do aluno de classe baixa em sala de aula pode potencializar o fracasso escolar deste. Os procedimentos metodológicos são explicitados pelo levantamento bibliográfico das produções do grupo de pesquisa NetEDU, chegando a aproximadamente 50 textos pertinentes à temática aqui lançada. A relevância deste estudo está na imersão nessa relação complexa do visível, do invisível, suas relações, opacidades e entrelaçamentos. Essa imersão extrapola a percepção para além do punctum caecum do binarismo visível ou invisível; as invisibilidades ou a invisibilidade.

PaLAVRas-ChaVe: Invisibilidade; Aluno; Sala de Aula.

\begin{abstract}
This article is based on an anthropological-visual reflection on the "power of the eye". It is understood that the question of the gaze reflects relations of power and consolidates them. Here we delimit to analyze the question of the "look" in the relations of power in the school space, specifically before the student of underprivileged conditions because it is understood that this is the object of a look that constitutes it in its otherness. We aim to investigate how the invisibility of the low-class student in the classroom can potentialize his school failure. The methodological procedures are explained by the bibliographic survey of NetEDU research group's productions, approximately 50 texts pertinent to the theme here addressed. The relevance of this study lies in the immersion in the complex relation between the visible, the invisible, its connections, opacities and interlacings. This immersion extrapolates the perception beyond the punctum caecum of visible or invisible binarism; invisibilities or invisibility.
\end{abstract}

KeYWORDS: Invisibility; Student; Classroom.

\footnotetext{
${ }^{1}$ Universidade do Estado do Rio de Janeiro. e-mail: nathaliabastos03@hotmail.com

${ }^{2}$ Universidade do Estado do Rio de Janeiro. e-mail: gabriellebrs1@gmail.com
} 


\section{INTRODUÇÃO}

Um dos maiores desafios da educação é proporcionar uma escola que seja, ao mesmo tempo de qualidade e democrática, isto é, que não ofereça aos pobres uma escolaridade pobre, mas que efetivamente consiga que todos os alunos, mesmo aqueles socialmente desprivilegiados, aprendam de forma equalitária.

Diante deste desafio que nos é antigo, Condorcet, um dos promotores em prol da estatização da escola, defende, em 1792, que a escola deve permitir a "qualquer criança, em função das suas próprias capacidades, chegar à melhor situação social possível, e que os critérios de seleção e de orientação são por isso intrínsecos à personalidade do aluno e não sofrem o efeito da origem social" (VAN HAECHT, 2001, p. 13). Em outras palavras, é importante destacar que a educação se articula a diferentes dimensões e espaços da vida social sendo assim, elemento constitutivo e constituinte das relações sociais em que fazemos parte. A educação, portanto, perpassa os limites e possibilidades da dinâmica pedagógica, econômica, social, cultural e política de uma dada sociedade.

Porém, existem alguns percalços a serem superados. O primeiro deles é a escola pertencer a uma estrutura social permeada de mecanismos de exclusão. É importante destacar então, o que concerne à sociedade e o que se refere à escola. Assim, nos questionaremos qual seria o lugar da escola numa estrutura social que desenvolve processos de exclusão. O segundo percalço concerne à análise dos mecanismos propriamente escolares que acabam por estabelecer uma segmentação escolar, podendo determinar a formação dos percursos de exclusão.

A análise do papel da escola nos mecanismos de exclusão escolar implica isolar os mecanismos e os fatores pelos quais a escola pode "aumentar" e aliar aos fatores de desigualdade e de exclusão que ultrapassam a reprodução das desigualdades sociais. Diante do exposto, pode-se pensar que, se a soma desses "fatores escolares" não constituem nem a única nem a principal causa da exclusão, representa, entretanto uma instância que não pode ser negligenciada.

O problema da exclusão não é saber, de maneira mais incisiva ou não, quem é excluído, mas de conhecer também quais os processos e os efeitos dessa exclusão para os envolvidos. Dentre todos os processos que podem desencadear a exclusão e consequentemente o fracasso escolar, este artigo visa abordar a questão da invisibilidade do aluno em sala de aula, mas em uma concepção que não está restrita ao ver ou ao não ver e sim que compreende o ser (ente) enquanto é: ser. Possui-se uma visão do ser/estar na escola através das possibilidades de (in) visibilidade por meio das relações de poder que são construídas na escola.

De acordo com Cunha (2007), o termo invisibilidade, em sua origem, sob um enfoque etimológico, vem do latim invisibilis, originário de visibilis que se traduz por conhecer ou perceber (percipere) pela visão, olhar (videre) para contemplar. No Dicionário de Usos do Português do Brasil e baseando-se em Borba (2002), significa qualidade do que é invisível ou inacessibilidade aos sentidos, imperceptibilidade; é 


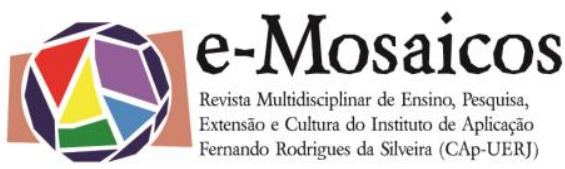

DOI: 10.12957/e-mosaicos.2018.29933

invisível aquilo ou aquele que não pode ser visto; não percebido pela visão ou perceptível sem ser visto.

Este artigo parte de uma reflexão antropológica-visual sobre o "poder do olhar". Entende-se que a questão do olhar reflete relações de poder e as consolidam. Os alunos de condições desprivilegiadas são objetos de um olhar que os constitui na sua alteridade. Infelizmente, essa realidade faz parte de uma ordem sócio espacial do olhar vigente em nosso cotidiano, onde busca-se por meio de formas como, "exibir", "ocultar" e "vigiar" a questão da visibilidade destes.

A escola, apesar de um direito a todos, não se destina a todos. Encontra-se aqui uma inquietação diante desse processo sob aqueles que não são percebidos, ou são esquecidos, marginalizados, silenciados e os que se escondem.

\section{Objetivos}

Diante deste contexto, investigar o como, como a invisibilidade do aluno de classe baixa pode potencializar o fracasso escolar deste constitui-se objeto de estudo deste artigo. O presente estudo, portanto, debruça-se sobre essa questão imprescindível para a educação, pois as concepções de professores e alunos sobre a escola são também determinantes de suas ações.

Para tanto, tem-se como objetivo, através dos estudos despendidos até o momento, averiguar os diferentes aspectos da invisibilidade do aluno e sua relação com a exclusão educacional. Assim como, analisar como se dá a seletividade escolar e como esta implica no fracasso escolar. Pretende-se concluir por hora, problematizando e questionando como a exclusão social e educacional implicam na produção do fracasso escolar.

Ressaltam-se aqui alguns questionamentos que nortearam a elaboração dos objetivos deste artigo. São perguntas sobre como é possível que determinadas práticas existam enquanto são veladas em seus discursos. Ao perceber estas possibilidades nos surgimento/ocultamento dos alunos e alunas em suas relações, inicia-se a reflexão sobre como estes sujeitos se desvelam no mundo-escola a partir do questionamento: Como o fenômeno da(s) (in)visibilidade(s) na escola surge $(m) / o c u l t a(m)$-se nos cenários em sala de aula? Como esse fenômeno se relaciona com o fracasso escolar? Quem fracassa no fracasso escolar? Existe um perfil pré-determinado de uma escola e de um aluno que fracassam? Quais têm sido as práticas definidoras ou medidoras do fracasso escolar? Assume-se então, como questão central a invisibilidade dos alunos na sala de aula e suas consequências.

A relevância deste estudo está na imersão nessa relação complexa para a compreensão do visível, do invisível, suas relações, opacidades e entrelaçamentos. Essa imersão extrapola a percepção para além do punctum caecum (ponto cego) do binarismo visível ou invisível; as invisibilidades ou a invisibilidade. 


\section{Metodologia}

Tomar como objeto de estudo a invisibilidade do aluno na sala de aula permite refletir sobre como os indivíduos, os grupos, os sujeitos sociais constroem seu conhecimento a partir de sua inscrição social, cultural etc (Giddens, 1997). Em resumo, como se dá a interação entre os sujeitos e a sociedade na construção da realidade, segundo Berger e Luckmann (2000), e como terminam por (des) construíla em uma estreita parceria que, indubitavelmente, passa pela interação.

Os procedimentos metodológicos da pesquisa são explicitados através do levantamento bibliográfico das produções do grupo de pesquisa NetEDU (Núcleo de Etnografia em Educação) da Universidade do Estado do Rio de Janeiro, Coordenado pela Professora Carmen Lúcia Guimarães de Mattos do qual faço parte desde o ano de 2014. Foi elaborado um banco de dados que possui aproximadamente 600 textos que abarcam temáticas da educação e vertentes que se referem ao fracasso escolar, repetência, exclusão social e escolar entre outros. Deste levantamento, foi elaborado um segundo banco de dados para a dissertação que dá origem a este artigo. Neste segundo banco de dados, foram elencados aproximadamente 50 textos que se aproximavam da temática aqui lançada. Foram levantados textos relativos ao tema em questão, isso diz respeito à construção da invisibilidade do aluno nas relações marcadas pelo poder, que podem ocorrer no contexto da relação professor-aluno.

Esse estudo não tem, de forma alguma, como pretensão, ser uma gênese do conhecimento sobre as concepções e práticas na relação professor e aluno em sala de aula. Antes, admite suas limitações, porém, diligentemente busca de forma minuciosa averiguar os procedimentos sociais e discursivos, presentes na edificação da invisibilidade do aluno na práxis escolar.

A intenção, ao enunciar as categorias segundo as palavras de Alves-Mazzotti (1998), é diminuir a iminente possibilidade de o pesquisador vir a se perder em um emaranhado de dados sem conseguir chegar ao final com o significado claro do problema. Os termos tomados como essenciais e admitidos como categorias eleitas para essa pesquisa são "invisibilidade" e "fracasso escolar".

\section{DISCUSSÃO TEÓRICA}

De acordo com o fundamento teórico escolhido para este estudo, compreende-se que é de grande relevância o aprofundamento na relação entre professor e aluno e sua relação com a (in)visibilidade deste segundo, assim como a relação entre a invisibilidade e o fracasso escolar tendo em vista a importância dessa relação no espaço escolar.

Conhecer a escola na sua estrutura significa colocar uma lente de aumento na dinâmica das relações e interações que constituem o seu dia-a-dia, apreendendo as forças que impulsionam ou que a retêm, 


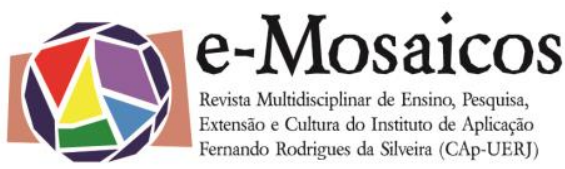

DOI: $10.12957 /$ e-mosaicos.2018.29933

identificando as estruturas de cada sujeito nesse complexo de interrelação onde ações, relações, conteúdos são construídos, negados reconstruídos ou modificados (ANDRÉ, 1995, p. 78).

O espaço escolar, anteriormente mencionado, é um sistema de ensino permeado de relações de poder e tem como eixo o poder simbólico, este podendo ser compreendido como um poder invisível "que só pode ser exercido com cumplicidade daqueles que não querem saber que the são sujeitos ou mesmo o exercem" (BOURDIEU, 1989, p. 8). Assim, a sala de aula é o espaço no qual se travam batalhas pelo/de poder e se estabelecem relações de poder, de forma clara, implícita, e, por vezes impositiva. Esse poder é quase mágico, pois permite obter o equivalente quando se usa a força, graças ao efeito específico de mobilização.

Sabe-se que a essência da educação consiste em enquadrar pessoas às normas sociais consideradas ideais pela sociedade. Afinal, todas as ciências humanas definem os seres humanos em vez de descrevê-los, produzindo categorias de normalização e de conduta desviante.

Da normalidade constitui a via principal em que se estabelece a relação de poder, pois quando se define uma anormalidade, com sua correspondente norma, sempre de uma maneira ou de outra, a pessoa normal tem poder sobre o anormal. Portanto, pode-se entender que a questão da invisibilidade cumpre um papel social definido por um dado contexto histórico e social (FILLIGHAM; SUSSER, 1999, p. 20).

Indaga-se aqui, então, sobre e a partir de que momento as condições que tornaram uma diferença social (ou cultural) em uma desigualdade social (ou cultural) visto que nem toda diferença social constatada é interpretável em termos de desigualdade social. É nesse sentido que a questão da invisibilidade ganha melhor compreensão, pois, existe uma regulação e um controle em nosso olhar, para onde e para quem o direcionaremos, "quem somos nós e quem são os outros [...] como somos nós e como são os outros" (SKLIAR, 2005, p. 71). Entende-se que a invisibilidade ganha pela negação da realidade do espaço.

E um outro cuidadosamente pronunciado, um outro gramaticalmente correto. O outro está bem enunciado, mas capturado em uma mesmidade que se mascara em maneiras ligeiras de dizer, de nomear e de olhar. Um outro anunciado, as a distância, isento de toda relação, ignorado em seu olhar, em seu dizer, em seu respirar [...] o mundo do politicamente correto é um mundo onde não seria melhor não nomear o negro, não chamar o deficiente de deficiente, onde não seria melhor chamar o índio de índio. É o mundo do eufemismo, do travestismo discursivo. Não nomeá-los, não dizê-los, não chamá- 


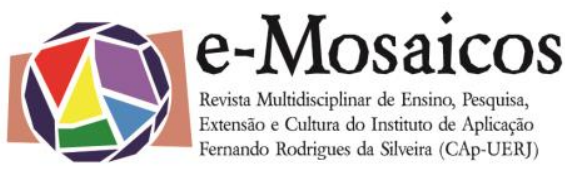

DOI: $10.12957 /$ e-mosaicos.2018.29933

los, mas manter intactas as representações sobre eles, os olhares em torno deles (SKLIAR, 2005, p. 80).

Esse é o contexto que o presente trabalho objetiva questionar: as práticas adotadas e os mecanismos de exclusão que estas podem ocasionar. Para tanto, é preciso repensar de que maneira a relação professor e aluno produz exclusão, tornando invisíveis os atores envolvidos, no caso, os estudantes silenciados frequentemente em sua individualidade e cultura. $O$ que se vê no cotidiano de sala de aula é que, de início, os alunos já são rotulados como incapazes pelos professores, acabando por interiorizarem esse estigma de fracasso, começando a corresponder à expectativa negativa em torno do mito da inadequação, ou seja, promovendo a invisibilidade.

Esses juízos negativos que muitos professores formam de seus alunos manifesta-se de duas maneiras: objetivamente e subjetivamente. Objetivamente, através de notas, conceitos e classificações e subjetivamente, através dos comentários, mímicas de desagrado, irritação, intolerância e desprezo (COSTA, 2002, p. 7).

Para os alunos dos meios sociais mais desfavorecidos, a escola, ao mesmo tempo em que se "conquista", se "perde", pois, nela, estão ao mesmo tempo, relegados para os espaços mais indesejáveis, para as fileiras mais desprestigiadas e por fim para os diplomas de menor valor econômico e simbólico. Corroborando a esse pensamento, Bourdieu e Champagne (1992), alega que a escola atual, ao guardar no seu interior aqueles que exclui, gera os "excluídos do interior".

Ou seja, dependendo da maneira como o professor maneja sua aula, a pedagogia em questão pode negar a experiência e história do aluno, reduzindo a aprendizagem a uma dinâmica de transmissão e imposição. Portanto,

a invisibilidade da realidade das classes populares e das diferenças étnicas nos conteúdos curriculares faz com que, aos poucos, estes se tornem gradativamente desinteressantes e irrelevantes para os/as alunos/as que neles não se encontram reconhecidos (CANDAU, 2003, p. 44).

Logo, percebe-se que: as classificações, categorias e rótulos que perpassam a sociedade não acontecem aleatoriamente; ao contrário, estão diretamente relacionados aos aspectos sócio-político-econômicos de um dado momento e contexto histórico. Sendo assim, esses aspectos possuem grande relevância em relação à construção das subjetividades, ou seja, "o aluno só escolhe dentro do que Ihe resta a escolher em função das suas performances [...] [e] encontra-se envolvido num processo de exclusão relativa" (DUBET, 1996, p. 501). Assim, as representações 


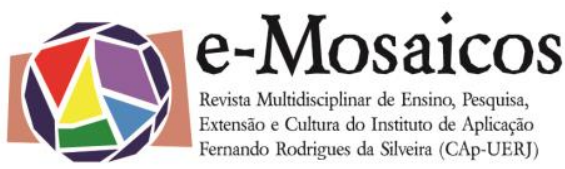

DOI: $10.12957 /$ e-mosaicos.2018.29933

que temos variam segundo a posição que temos e segundo nosso habitus como sistema de esquemas de percepção e apreciação, como estruturas cognitivas e avaliatórias que adquirimos pela experiência através da nossa posição do mundo social. Em consequência, o habitus produz práticas e representações que estão sujeitas à classificação e objetivamente diferenciadas, julgadas e hierarquizadas.

Para Skliar (2005), todo ato de classificação tem um sentido perverso, pois representa em si mesma, as categorias de exclusão e inclusão, nas quais supõe a existência de coerção e violência.

Podemos dizer agora que toda espacialidade produzida e inventada normalizada, traduzida e/ou representada como espaço único de inclusão e exclusão é um ato de perversão. Perversão na insistência do mesmo e perversão na eterna reprodução do outro como o mesmo. Dois lados, quase idênticos, da perversão da mesmidade. Perversão de só poder ser dentro e de só poder ser fora (e caro que se trata de um só poder que sempre se move de forma volátil, efêmera e provisória [...] perversão de rejeitar, impedir, proibir os nãoespaços, a falta de espaços, os espaços híbridos, as fronteiras, a passagem entre fronteiras, a vida nas fronteiras, os espaços outros (SKLIAR, 2005, p. 66).

O que parece é: não temos, nunca, compreendido o outro. Mas o temos, sim, massacrado, ignorado, excluído e incluído com o intuito de negar a invenção do outro, prefere-se hoje afirmar que estamos frente a um novo sujeito. Mas, é preciso dizer: um novo sujeito da mesmice. Mutiplicam-se suas formas de identidades porém, são autorizados, respeitados, aceitos e tolerados apenas uns poucos fragmentos da sua alma. Assim, o outro da educação foi sempre um outro que devia ser anulado e apagado. A pedagogia do outro que deve ser anulado é aquela que diz ao outro: "Está mal ser o que és", e que considera esta mensagem como o seu único ponto de partida. Está mal em ser índio, ser surdo, ser mulher, ser negro, menino da rua, jovem etc. É também, a pedagogia que adota como ponto de chegada outra mensagem para o outro: "está bem ser alguma coisa que nunca poderá ser - está bem ser branco, ouvinte, homem, adulto, etc". Essas formas de narrar a alteridade são formas de representação que diluem os conflitos e que delimitam os espaços por onde se pode transitar. Porém, se a cultura é, de acordo com Bhabha (1994), um território de diferenças que precisa de permanentes traduções, o problema crucial é quem traduz a quem e através de que significados. Essas formas não são neutras nem opacas gerando assim, consequências na vida dos envolvidos. O problema da representação então, é que existe uma regulação e um controle do olhar que define quem são e como são os outros. Neste sentido, visibilidade e invisibilidade constituem mecanismos de produção da alteridade e atuam simultaneamente com o 


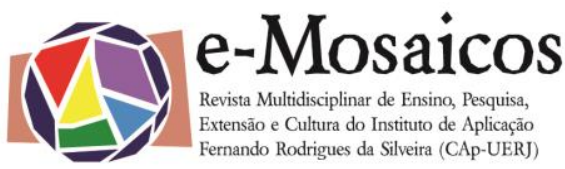

DOI: $10.12957 /$ e-mosaicos.2018.29933

nomear e/ou deixar de nomear. Coadunando a essa perspectiva, é interessante a ideia de Griselda Pollok (1994) acerca do "apelo à visão" que a representação impõe, isto é, existe uma relação social exercida através de manipulações específicas de espaços e corpos imaginários para o beneficio do olhar em relação ao outro.

A dificuldade em lidar com essa relação, de acordo com Jean Anyon (1981), se deve ao fato de ainda existir uma estratificação social do conhecimento pautada na classe social dos alunos que acaba criando condições para que as escolas se tornem ambientes reprodutores da sociedade e, ao mesmo tempo, cria empecilhos para mudanças sociais. Em suma, defende-se como bem sintetizam Cacouault e Oeuvrard (2003, p. 54), que as "desigualdades sociais de sucesso escolar resultam das desigualdades de repartição do capital cultural". Ou seja, de acordo com Boudon (1973) a sobrevivência de um indivíduo no sistema escolar depende de um processo de decisão cujos parâmetros existem em função da posição social ou posição de classe.De acordo com o que foi exposto, percebe-se que pratica-se sobre o pobre uma exclusão social, que exclui o sujeito do acesso a bens sociais como a educação, e com isto se o mantém na condição social inferiorizada que Ihe foi determinada, ou seja, o que ocorre é uma tolerância de tais indivíduos, na medida que sua utilidade funcional, desde que bem marcada uma separação diferencial, os mantenha afastados.

\section{RESULTADOS}

O que percebe-se é que, por vezes, as apreciações dos professores são afetadas, mesmo que inconscientemente, pela condição social do aluno e, deste modo, acrescentam às dificuldades já existentes da diferenciação cultural sentidas pelos alunos dos meios populares um novo obstáculo a vencer: as representações e expectativas negativas referentes a sua aprendizagem. Como afirma Duru-Bellat (2002, p. 236), "a definição do mérito é sempre subjetiva e contextualizada e não é mais do que um julgamento social". Diante destas representações, existe uma preocupação referente à submissão por parte dos alunos a esse julgamento social e escolar visto que isso pode vir a tornar eficaz conforme a força de imposição simbólica: "quanto maior e mais brutal for a coação exercida, mais intensa deve ser a persuasão simbólica que a legitime perante os dominados" (BARTOLOMÉ RUIZ, 2004, p. 56). Essa preocupação se justifica visto que o indivíduo cuja subjetividade se constitui no sentido de inferiorização, na forma descrita acima, tem a sua exclusão social operacionalizada sob formas várias: vedação de acesso à educação, nas relações sociais, ao crescimento econômico, sendo assim destinado a locais sociais especificos e limitados onde é acentuada a sua condição de Outro.

Nesta condição, a pessoa vai perdendo a capacidade de não se resigna e e não esboça nenhuma reação, submetendo-se por completo, a ponto de considerar-se alijada do contexto social, por que acredita que as instituições estão a serviço dos direitos que pertencem a uma outra categoria de pessoas, da qual ela não faz parte. Nesse caso, opera-se a normalização da condição inferiorizada do sujeito. 
DOI: $10.12957 /$ e-mosaicos.2018.29933

Através desta postura passiva, o sujeito autoexcluído manifesta uma inércia comportamental pela qual submete-se voluntariamente a uma conduta ditada pelo poder normalizador, sem questioná-la sequer intelectualmente e, menos ainda, de forma efetiva, pela busca de seus direitos, configurando uma violência contra o exercício da cidadania. Portanto, vê-se aqui o desejo de argumentar a favor de uma pedagogia crítica que leve em conta como as transações simbólicas e materiais do cotidiano fornecem base para se repensar a forma como as pessoas dão sentido à substância ética, às suas experiências e vozes. Vozes silenciadas, que alcançam a dimensão da invisibilidade, pelo fato de o currículo não contemplar o saber do aluno, no momento que o silencia, ignora, inferioriza, menospreza em favor dos interesses hegemônicos.

Sem deixar de respeitar os particularismos culturais, linguísticos e religiosos, o estado deve assegurar a todos o mínimo cultural comum, condição do exercício duma atividade profissional bem sucedida e da manutenção do mínimo de comunicação indispensável ao exercício esclarecido dos direitos do homem e do cidadão (BOURDIEU, 1987, p. 110).

\section{REFERÊNCIAS}

ALVES-MAZZOTTI, A. J. Revisão da bibliografia. In: ; GEWANDSZNAJDER, Fernando. $O$ método nas ciências naturais e sociais. pesquisa quantitativa e qualitativa. São Paulo: Pioneira, p.179-188, 1998.

ANDRE, M. E. D. A. Etnografia na prática escolar. Campinas, São Paulo, Papirus, 1995. BARTOLOMÉ RUIZ, C. M. M. Os labirintos do poder: o poder (do) simbólico e os modos de subjetivação. Porto Alegre: Escritos Editora, 2004.

BERGER, P. L.; LUCKMANN, T. A construção social da realidade. 19. ed. Tradução de Floriano de Souza Fernandes. Petrópolis: Ed. Vozes, 2000.

BHABHA, H. R. O local da cultura. Trad: Ávila Miriam et al., Belo Horizonte, UFMG, 1998.

BORBA, F. S. Dicionário de Usos do Português do Brasil. 1 ed. São Paulo: Editora Ática, 2002.

BOURDIEU, P.; CHAMPAGNE, P. "Les exclus de I'intérieur", Actes de la Recherche em Sciences Sociales, pp. 71-75, 1992.

BOURDIEU, P. Choses dites. Paris: Les Éditions de Minuit, 1987. 
. O poder simbólico. Tradução de Fernando Tomaz. 6. ed. Rio de Janeiro:

Bertrand Brasil, 1989.

CACOUAULT, M.; OEUVRARD, F. Sociologie de /'Éducation, Paris, Éd. La Découverte, 2003.

CANDAU, V. M. (Coord). Somos Todos iguais? Escola, discriminação e educação em direitos humanos. Rio de Janeiro: DP\&A, 2003.

COLLARES, C. A. L.; MOYSÉS, M. A. A. Preconceitos no cotidiano escolar: Ensino e medicalização. São Paulo, Cortez, 1996.

COSTA, R. A. Disciplina na escola: adolescência e constituição da subjetividade. Rio de Janeiro: E-Papers Serviços Editoriais, 2002.

CUNHA, A. G. da. Dicionário etimológico da língua portuguesa. Rio de Janeiro: Lexikon Editora Digital, 2007.

DOUDON, R. L'Inegalité des Chances. La Mobilité Sociale dans les Sociétés Industrielles, Paris, Armand Colin, 1973.

DUBET, F. "L'exclusion scolaire: quelles solutions?", em S. Paugam (org.), L'Exclusion. État des Savoirs, Paris, Éd. La Découverte, 1996.

FILLINGHAM, L. A.; SUSSER, M. Foucault para principiantes. Buenos Aires : Era Naciente, 1999.

GIDDENS, A. Modernização reflexiva: política, tradição e estética na ordem social moderna. Trad. Magda Lopes. 2. ed. São Paulo: Ed. da Universidade Estadual Paulista, 1997.

POLLOCK, G. Feminism/Foucault-Surveillance/Sexuality. In: BRYSON N., HOOLY M. e MOXEY K. (Eds). Visual culture: image and interpretations. Hannover: Wesleyan University Press, 1994.

SKLIAR, C. A invenção e a exclusão da alteridade "deficiente" a partir dos significados da normalidade. In: Educação e Realidade. Porto Alegre: Universidade Federal do Rio Grande do Sul, Faculdade de Educação, v. 37, 2005.

VAN HAECHT, A. L 'École des Inégalités. Éssai sur les Politiques d'Éducation, Mons, Éd. Talus d'Approche, 2001.

Recebido em 10 de agosto de 2017. Aceito em 05 de outubro de 2017. 